\section{Case Reports in Neurology}

\title{
Myointimal Hyperplasia in a Patient with Neuromyelitis Optica (Devic's Disease) after the Creation of an Arteriovenous Graft
}

\author{
Christina Rao ${ }^{a}$ Stephanie Fox ${ }^{b}$ Sapan S. Desai ${ }^{b}$ \\ ${ }^{a}$ Washington University of St. Louis, St. Louis, MO, USA; ${ }^{b}$ Department of Vascular Surgery, \\ Northwest Community Hospital, Arlington Heights, IL, USA
}

\section{Keywords}

Neuromyelitis optica - Devic's disease - Myointimal hyperplasia - Autoimmune disease . Plasmapheresis

\begin{abstract}
Neuromyelitis optica, also known as Devic's disease, is an autoimmune disorder that leads to the inflammation and demyelination of nerves. Devic's disease primarily affects the optic nerve and spinal cord, but can lead to a significant loss of function throughout the body if not treated with steroid therapy or plasmapheresis. We recently saw a 62-year-old patient who received plasmapheresis for Devic's disease through a PTFE arteriovenous graft in her left arm. Her graft clotted without warning, and percutaneous thrombolysis was not successful. A new vascular access was achieved with the use of an immediate-cannulation PTFE graft, and the patient received plasmapheresis immediately after her operation. However, the patient returned within 2 weeks with a thrombosed graft. Extensive myointimal fibrosis was noted within the brachial artery and axillary vein during a graft thrombectomy. Subsequent placement of a new arteriovenous fistula in her contralateral arm was eventually successful. Myointimal fibrosis may be a sequela of symptomatic antibody-positive Devic's disease, and avoidance of synthetic materials may be indicated in this patient population to avoid exacerbation of an autoimmune response.




\section{Case Reports in Neurology}

\begin{tabular}{l|l}
\hline Case Rep Neurol 2017;9:252-255 \\
\hline DOI: $10.1159 / 000480230$ & $\begin{array}{l}\text { C 2017 The Author(s). Published by S. Karger AG, Basel } \\
\text { www.karger.com/crn }\end{array}$ \\
\hline
\end{tabular}

Rao et al.: Myointimal Hyperplasia in a Patient with Neuromyelitis Optica (Devic's Disease) after the Creation of an Arteriovenous Graft

\section{Introduction}

Devic's disease is an autoimmune syndrome that leads to the progressive inflammation and demyelination of nerves in the central nervous system. This disease primarily affects the optic nerve and the spinal cord, though more recent studies have shown that systemic effects can be common. Devic's disease is often confused with multiple sclerosis (MS) as both are autoimmune diseases with similar symptoms [1,2]. However, Devic's disease does not have the characteristic MRI changes seen in MS, but can sometimes be distinguished by the presence of a neuromyelitis optica (NMO)-IgG biomarker that is present in the serum [1-5]. While the prevalence and incidence of Devic's disease is unknown, it appears to be more common in women with an average age at onset of 40 years [1].

Devic's disease does not progress in the manner which diseases like MS do. Patients with Devic's disease typically have a relapsing course with intermittent but progressive deficits $[1,2]$. Plasmapheresis is often used to treat patients inflicted with Devic's disease after the use of corticosteroids has been proven ineffective [1, 3, 6]. Anti-AQP4 antibody serum levels decline significantly following plasmapheresis, proving it to be an effective treatment for the majority of patients with Devic's disease [6]. Permanent access for plasmapheresis is achieved through the placement of an arteriovenous fistula or graft (AVG).

\section{Case Report}

Our patient is a 62-year-old woman with a history of anemia, deep vein thrombosis, anxiety, and Devic's disease. After an initial misdiagnosis of MS, she was found to have Devic's disease when she tested positive for the NMO-IgG biomarker in her serum. She has required plasmapheresis as her primary treatment for her Devic's disease due to the failure of corticosteroid treatment. She received plasmapheresis via a left arm brachial-axillary PTFE AVG that has been in place for 10 years and used without incident.

In May 2017, the patient developed acute thrombosis of her AVG. Thrombolysis was completed, but the graft clotted off again within 1 week. She was seen and evaluated in our clinic for placement of a new dialysis access in June 2017, and we elected to create a new right arm AVG using an immediately cannulable graft (Acuseal, W.L. Gore \& Associates, Flagstaff, AZ, USA) [7]. This was placed in a brachial-axillary configuration with the brachial artery connected to the axillary vein via a trilayer PTFE graft. There were no issues during the operation, and Doppler ultrasound confirmed a widely patent graft at the conclusion of the case. The patient was able to use this graft for plasmapheresis immediately after surgery.

The patient presented to our clinic 2 weeks after surgery for a routine postoperative visit. During this visit, it was noted that the graft was thrombosed, and there was now an absence of a radial and ulnar pulse. The patient was asymptomatic, and thus elective open thrombectomy of the graft was scheduled. This procedure was completed in late June 2017; during this procedure, we were unable to pass the Fogarty thrombectomy catheter past either the arterial or venous anastomoses. Open exploration of both anastomotic sites was then performed and severe myointimal fibrosis was noted within both the brachial artery and the axillary vein. While the axillary vein was completely obliterated by this reaction, a portion of the brachial artery remained patent. A patch angioplasty was completed using a native vein, and pulsatile flow to the radial and ulnar arteries was obtained. The graft was excised as it was no longer functional. 


\section{Case Reports in Neurology}

Rao et al.: Myointimal Hyperplasia in a Patient with Neuromyelitis Optica (Devic's Disease) after the Creation of an Arteriovenous Graft

An open exploration of her prior left arm AVG was completed to determine whether this graft could be utilized for dialysis. A similar myointimal fibrotic reaction was seen here as well, affecting both the left brachial artery and axillary vein. A portion of this tissue was sent to pathology for evaluation, which revealed the presence of a myointimal fibrotic reaction. A temporary dialysis access was then obtained. The patient was started on a 5-day steroid taper during this period, and the patch angioplasty of the brachial artery remained patent 3 months after the procedure.

The patient was brought back to the operating room 2 weeks later for the establishment of a new left arm brachiocephalic arteriovenous fistula. This fistula matured successfully and is now being used for hemodialysis without any issues.

\section{Discussion}

The AQP4-seropositive form of Devic's disease is related to an autoimmune response [4]. The body's own immune system attacks the AQP4 proteins in the astrocytes of cell membranes [3]. Patients with Devic's disease have a higher prevalence of Th17 cells than patients with MS or normal healthy volunteers [8]. Th17 cells are cells that secrete interleukin and transforming growth factor-beta; as transforming growth factor-beta causes fibrosis, this may be the mechanism of action that leads to myointimal fibrosis in patients with Devic's disease $[8,9]$. The sudden thrombosis of a graft that had been used without incident for over a decade, followed by an acute myointimal fibrosis in a new graft, may be secondary to the hyperactive autoimmune reaction that can occur in Devic's disease $[4,8,10]$.

Devic's disease is poorly studied due to its rare nature and difficult diagnosis. The presence of an aggressive myointimal fibrotic reaction may indicate a particularly vulnerable subset of patients. Artificial materials should be minimized in these patients, as they may precipitate an aggressive autoimmune reaction. Some of these adverse effects could potentially be ameliorated through the use of steroids during the perioperative period, as we did when completing the patch angioplasty of the brachial artery. The use of PTFE, meshes, and implants should thus be carefully weighed against the risk of arterial and venous occlusion due to fibrosis, and scar tissue formation in other parts of the body. Patients with Devic's disease who require arteriovenous access for plasmapheresis may therefore benefit from autologous access via a direct fistula between an artery and vein, instead of the placement of a synthetic graft.

\section{Statement of Ethics}

The patient has given her informed consent to publish this report.

\section{Disclosure Statement}

The authors have no conflicting interests. 
Rao et al.: Myointimal Hyperplasia in a Patient with Neuromyelitis Optica (Devic's Disease) after the Creation of an Arteriovenous Graft

\section{References}

1 Weinshenker BG, Wingerchuk DM: Neuromyelitis spectrum disorders. Mayo Clin Proc 2017;92:663679.

2 Wingerchuk DM, Banwell B, Bennett JL, Cabre P, Carroll W, Chitnis T, De Seze J, Fujihara K, Greenberg B, Jacob A, Jarius S, Lana-Peixoto M, Levy M, Simon J, Tenembaus A, Traboulsee A, Waters P, Wellik K, Weinshenker BG: International consensus diagnostic criteria for neuromyelitis optica spectrum disorders. Neurology 2015;85:177-189.

3 Palakuru S, Boka K: A rare cause of cardiac arrest-Devic's disease. Am J Respir Crit Care Med 2017;195:A2019.

-4 Lennon VA, Wingerchuk DM, Kryzer TJ, Pittock SJ, Lucchinetti CF, Fujihara K, Nakashima I, Weinshenker BG: A serum antibody marker of neuromyelitis optica: distinction from multiple sclerosis. Lancet 2004;364:2106-2112.

5 Lucchinetti CF, Guo Y, Popescu BFG, Fujihara K, Itoama Y, Misu T: The pathology of an autoimmune astrocytopathy: lessons learned from neuromyelitis optica. Brain Pathol 2014;24:83-97.

6 Kim S, Kim W, Huh S, Lee KY, Jung IJ, Kim HJ: Clinical efficacy of plasmapheresis in patients with neuromyelitis optica spectrum disorder and effects on circulating anti-aquaporin-4 antibody levels. J Clin Neurol 2013;9:36-42.

7 Tozzi M, Franchin M, Ietto G, Soldini G, Carcano G, Castelli P, Piffaretti G: Initial experience with the Gore ${ }^{\circledR}$ Acuseal graft for prosthetic vascular access. J Vasc Access 2014;15:385-390.

-8 Wang HH, Dai YQ Lu ZQ, Peng PH, Wang YG, Bao J, Li Y, Hu XQ: Interleukin-17-secreting T cells in neuromyelitis optica and multiple sclerosis during relapse. J Clin Neurosci 2011;18:1313-1317. Korn T, Bettelli E, Oukka M, Kuchroo VK: IL-17 and Th17 cells. Ann Rev Immunol 2009;27:485-517. Kister I, Gulati S, Boz C, Bergamaschi R, Piccolo G, Oger J, Swerdlow ML: Neuromyelitis optica in patients with myasthenia gravis who underwent thymectomy. Arch Neurol 2006;63:851-856. 